\title{
IBM and Apple set up camp
}

\section{Washington}

IN one of the most important developments yet in the consolidation of the US computer industry into a handful of competing camps, the two main US personal computer manufacturers, IBM and Apple, last week signed a letter of intent to cooperate in developing hardware and software for the next generation of desktop computers.

If successful, the alliance promises to provide computer users with faster desktop machines, capable of doing many tasks at a time. Although other consortia are also working to this end, the competitive spur provided by the new link-up may accelerate the appearance on the market of faster machines. It should also become possible to use Apple's Macintosh machines as terminals to work on IBM mainframes, producing easier-to-use computing networks for the many computer users who have grown accustomed to Apple's graphically based systems.

With the costs of research and development in the computer industry forever rising, and the profit margins of the major companies being squeezed by advent of smaller companies selling cheap 'clones' of the leading designs, the formation of strategic alliances has become a general trend.

The most significant feature of the wide-ranging IBM and Apple technology agreement is the announcement that the two companies will work together to develop a new personal computer operating system (the software that controls a computer's basic functions), using object

oriented programming techniques. This operating system will be designed to run on a range of different machines.

The agreement's other main component is the decision to further refine IBM's state-of-the-art reduced instruction set computing (RISC) microprocessor, one of the fastest microchip designs available. Motorola will develop more compact and cheaper versions of IBM's RISC chip, for use in future IBM and Apple computers. Greater computing speed may allow future desktop computers to run programs combining text, graphics and video so-called 'multimedia' computing.

While most industry analysts agree that successful collaboration between IBM and Apple would redefine the landscape of the US computer industry, there is still some scepticism about the likely success of the arrangement.

Contracts to formalize the collaborations described in the letter of intent have yet to be thrashed out, and several muchheralded computer industry alliances signed in the past have not yielded significant results.

The new IBM and Apple link may pose more problems than most prospective alliances, simply because of two companies' differing business styles. IBM has traditionally been seen as a rather staid organization no bad thing when a company's principal market is the conservative world of corporate America. By contrast, the California-based Apple has presented itself as a pioneering, freespirited company, ever ready to take risks.

Peter Aldhous

\section{A European collaboration for IBM}

InTERnATIONAL Business Machines (IBM) and Siemens of Germany will join forces to manufacture next generation computer memory chips, a move aimed at challenging Japanese domination in that market. The news came on 4 July, just one day after IBM announced a major collaboration with Apple Computer to develop personal computers and work stations (see above).

The IBM-Siemens agreement is likely to alter the balance of the chip-making industry worldwide, and particularly in Europe. It ends the chance of a merger or close collaboration between Europe's three major semiconductor manufacturers, Siemens, Philips Electronics of the Netherlands and SGS-Thomson Microelectronics of France and Italy - a strategy urged by some as a way to create a purely European semicon- ductor concern able to compete on equal terms with US and Japanese companies. But because IBM and Siemens are leaving the door open for other partners, their agreement may allow European chipmakers access to state-of-the-art technology and could eventually increase Europe's competitiveness in the semiconductor field.

IBM and Siemens will expand an existing IBM semiconductor plant in France to produce 16-megabit dynamic random access memory chips, or DRAMs. The two companies will share the $\$ 700$ million cost of construction. The chips will be made according to an IBM design and with IBM manufacturing technology; Siemens will provide engineers and expertise. Production should begin late next year.

Robert Pool

\section{Red flag on CFC substitute Washington}

ONE of the most promising candidates to act as a replacement for ozone-destroying chlorofluorocarbons (CFCs) has been found to cause benign tumours in rats.

As a result, one US company has suspended marketing the chemical, HCFC123, and a second has halted production of equipment designed to use it. Although Du Pont, the largest producer of CFCs, continues to use HCFC-123, the evidence does raise some 'red flags' and indicates that the process of introducing CFC replacements may not be as smooth as thought.

HCFC-123 had been hailed as a nearly ideal substitute for CFC-11, which is widely used as a coolant in 'chillers', large commercial and industrial airconditioning systems. The two substances have very similar chemical and physical properties, and although HFCF-123 is more expensive than CFC-11, it does only a fraction of the damage to the ozone layer.

As a final step in the testing of HCFC123, a consortium of CFC manufacturers paid for a two-year test of its effects on rats. Three groups of rats were exposed to varying levels of the chemical in the air they breathed, while a fourth, unexposed group acted as controls. The most highly exposed rats breathed air that contained 5,000 parts per million (p.p.m.) $\mathrm{HCFC} 123$ for six hours a day, five days a week, for two years; roughly equal to a human exposure of 10 p.p.m. for eight hours a day, five days a week, for 30 to 40 years.

At the end of the two years, 66 male rats in the highest-exposure group had developed 10 benign pancreatic tumours compared with none among 67 controls, and 14 benign tumours in the testes compared with four in the controls.

Except for the tumours, the rats exposed to HCFC-123 were actually healthier than the controls, says Anthony Vogelsberg at Du Pont. Among the control group, only 26 per cent were alive after two years, whereas 59 per cent of those exposed to 5,000 p.p.m. of HCFC-123 survived the study.

The apparent beneficial effects notwithstanding, the presence of the benign tumours signals a potential hazard of HCFC-123 use, and in a letter to the Environmental Protection Agency, scientists from the consortium of $\mathrm{CFC}$ producers said they were lowering their recommended maximum human exposure from 100 p.p.m. to 10 p.p.m.

"We see no problem with its use in industrial chillers or in any applications where the exposure can be kept below the [10 p.p.m.] level," Vogelsberg says. Du Pont has been using HCFC-123 to aircondition its own buildings, he says, and experience has shown that even in the area around the chillers, the levels of HCFC123 are only 1 to 3 p.p.m. Robert Pool 